\title{
PROMOTERS STATE AND CATALYST ACTIVATION DURING AMMONIA SYNTHESIS OVER Ru/C
}

\author{
Ilenia Rossetti, Francesca Mangiarini and Lucio Forni ${ }^{\star}$ \\ Dip. Chimica fisica ed Elettrochimica, v. C. Golgi 19, 20133 Milano, Italy
}

\section{ABSTRACT}

Carbon-supported, promoted Ru-based catalysts for ammonia synthesis proved to be interesting substitutes for the traditional Fe-based ones. A debate recently arose on the active state of promoters, mainly $\mathrm{Cs}$ and $\mathrm{Ba}$, and on the effect of the latter on $\mathrm{Ru}$ active sites. In the present work a set of Ba-, Cs- and K-promoted samples has been characterised by various techniques. Higher $\mathrm{H}_{2}$ and $\mathrm{O}_{2}$ uptakes have been observed during reduction and chemisorption, respectively, on Cs- and K-promoted samples supported on graphitised carbon. No evidence of this has been observed with samples supported on active carbon. This is in line with the hypothesis of alkaline promoters partial reduction under the ammonia synthesis conditions, favoured by the formation of graphite intercalation compounds. Furthermore, some suggestions are here introduced on the beneficial role of $\mathrm{Ba}$, especially in increasing the support resistance to methanation. Finally, the efficacy of catalyst activation was found to depend on the nature of $R u$ precursor. Indeed, a prolonged activation at relatively high temperature is usually needed with chloride precursors, to remove the counterion, a poison for the catalyst, whereas less dramatic conditions are required for different precursors, such as nitrosylnitrate.

Keywords: Ammonia synthesis catalyst; Intercalation compounds; Temperature programmed reduction; Alkali metals reduction.

"Corresponding author: e-mail: lucio.forni@unimi.it, fax: +39-02-50314300. 


\section{1 - INTRODUCTION}

Ru-based catalysts raised interest in the last years as possible substitutes for the traditional Fe-based ones for the synthesis of ammonia [1-7]. Many possible formulations have been proposed, widely differing as for support (mainly active or graphitised carbon [2,4-6,8] and MgO [9-11]), Ru precursor (chloride [5,12,13], potassium ruthenate [2], carbonyls [14-16], nitrosylnitrate [17,18]) and promoters (alkali-, alkali-earth- and lanthanide-oxides).

In the recent past, a considerable body of papers aimed at throwing light on one of the key factors of this reaction on Ru-based catalysts, i.e. its structure sensitivity. It has been proposed that catalyst activity is dominated by Ru step sites, so called B5, whose concentration strongly depends on Ru particle size and hence on metal dispersion. Some work has been carried out both from a more theoretical point of view [8, 19-23] and from a more applicative approach [17].

As for promoters effect, since the earlier work of Aika and co-workers $[1,24]$ it is widely accepted that unpromoted Ru-based samples are almost completely inactive during ammonia synthesis, mainly when active or graphitised carbon is used as support, due to its electron-withdrawing effect [25]. Among the possible promoters, electron-donors are preferred, in order to facilitate electron transfer to $\mathrm{Ru}$ and so to enhance the rate of the rate-determining step of the reaction, i.e. the dissociative adsorption of $\mathrm{N}_{2}[3,26]$. However, more recently the interest was mainly focused on $\mathrm{Ba}, \mathrm{Cs}$ and $\mathrm{K}$ as possible promoters, leading to catalysts which allow overperforming the unpromoted samples, especially when added altogether, so to develop a synergistic effect [13,25].

The active form of $\mathrm{Ba}$ seems to be $\mathrm{BaO}[13,18,27]$, partly covering the $\mathrm{Ru}$ active particles, hence possibly exploiting a structural effect, by modifying the concentration and 
stability of surface sites. This promoter would indeed favour the exposition of crystallographic faces that are active for nitrogen adsorption, so favouring the formation of B5 sites [13,28]. A debate however arose around this hypothesis [18], the formation of B5 sites seeming similar for Ba-promoted and unpromoted samples. In this alternative view Ba was proposed essentially as electronic promoter [18,27].

The role of $\mathrm{K}$ and $\mathrm{Cs}$ is a bit clearer, their action being essentially of electronic nature. Indeed, alkaline metals play an electron-donor role even in their oxidised form [1] as evidenced by XPS experiments [25]. However, some recent new findings seem to point to the possible partial reduction of $\mathrm{Cs}$ and $\mathrm{K}$ to metal state during catalyst activation $[13,28,29]$. A highly reduced state has been so hypothesised $\left(\mathrm{Cs}_{\mathrm{x}} \mathrm{O}_{\mathrm{y}}\right)$, even down to the $\mathrm{Cs}$ metallic state.

Another reported difference between the various catalytic systems concerns catalyst activation before reaction, carried out under widely different conditions in order to get optimal catalytic performance. For example, a short activation route has been proposed [2,17], consisting in heating by $1^{\circ} \mathrm{C} / \mathrm{min}$ up to $450^{\circ} \mathrm{C}$, then kept for 5 hours, taken as example also by others [5]. By contrast, a much longer activation is reported e.g. in [13], consisting in reduction in $\mathrm{H}_{2}$ at $150^{\circ} \mathrm{C}$ for $16 \mathrm{~h}$, then at $350^{\circ} \mathrm{C}$ for the same time during catalyst preparation. Then, before reaction, the samples were further reduced in $\mathrm{H}_{2}+\mathrm{N}_{2}$ for $24 \mathrm{~h}$ at $400^{\circ} \mathrm{C}$, then for $24 \mathrm{~h}$ at either $430^{\circ} \mathrm{C}$ or at $470^{\circ} \mathrm{C}$, depending on the promoter. Furthermore, Hinrichsen et al. underlined the need of prolonged activation, so to attain the best catalytic performance [30], addressing short activation as the main cause of less good results.

The following questions can then arise about the effect of sample activation: $\iota$ ) can activation be useful for sample conditioning and for the reduction of the layer of passivated $\mathrm{Ru}$ only, or does it play a role in $\mathrm{Ru}$ redistribution in its active form (i.e. does it affect $\mathrm{Ru}$ 
dispersion)?; ii) is catalyst activation able to bring the alkaline promoter(s) to a reduced (metallic) state?; iii) what is the role of the carbon support in this scenario?

The goal of the present work was then to answer these questions by investigating a set of unpromoted, singly promoted and multiply promoted $\mathrm{Ru} / \mathrm{C}$ catalysts, prepared with two different supports, differing for their graphitisation degree. The promoters considered were $\mathrm{Cs}, \mathrm{Ba}$ and $\mathrm{K}$, used also for the preparation of blank samples (i.e. without $\mathrm{Ru}$ ) for comparison purposes. The samples were characterised by temperature programmed reduction and oxygen chemisorption and by performing many different activation treatments. Some activity tests, carried out after the different activation procedures, completed the present investigation.

\section{2 - EXPERIMENTAL}

\section{1 - Samples preparation}

All the samples were prepared by impregnation from aqueous solutions, using two different supports: a graphitised carbon, referred to as GC, with BET specific surface area $(\mathrm{SSA})=280 \mathrm{~m}^{2} / \mathrm{g}$, and a commercial active carbon, referred to as $\mathrm{AC}$, with SSA $=1400$ $\mathrm{m}^{2} / \mathrm{g}$. $\mathrm{Ru}$ was deposited from $\mathrm{Ru}(\mathrm{NO})\left(\mathrm{NO}_{3}\right)_{3}$ as described in detail elsewhere [17], achieving a final Ru/C loading of $3.8 \mathrm{wt} \%$. The sample was reduced in flowing hydrogen at $320^{\circ} \mathrm{C}$ for 5 hours. The Ru/GC sample was split into five portions, three of which were impregnated with only one single promoter ( $\mathrm{Cs}, \mathrm{Ba}$ or $\mathrm{K}$ ) using an aqueous solution of nitrate, the fourth was impregnated with the three promoters altogether and the fifth was left unpromoted. The promoters/Ru atomic ratios, optimised in a previous work [25] were $\mathrm{Cs} / \mathrm{Ru}=1, \mathrm{Ba} / \mathrm{Ru}=0.6, \mathrm{~K} / \mathrm{Ru}=3,5(\mathrm{~mol} / \mathrm{mol})$. A series of blank samples, i.e. without $\mathrm{Ru}$, was also prepared (Table 1). A comparative sample was prepared by impregnation from 
$\mathrm{RuCl}_{3} \cdot 3 \mathrm{H}_{2} \mathrm{O}$, reduced under the same conditions and promoted with $\mathrm{Ba}+\mathrm{Cs}+\mathrm{K}$ in the same optimal amount.

\subsection{Samples characterisation}

SSA was measured by $\mathrm{N}_{2}$ adsorption at $77 \mathrm{~K}$, using a Micromeritics ASAP 2010 apparatus. Temperature programmed reduction (TPR) was carried out by means of a home-made apparatus described in detail elsewhere [31]. The experiment was made on ca. $0.15 \mathrm{~g}$ of catalyst $\left(0.15-0.25 \mathrm{~mm}\right.$ particle size), in $5 \% \mathrm{H}_{2} / \mathrm{Ar}$ gas mixture, by heating $\left(10^{\circ} \mathrm{C} / \mathrm{min}\right)$ up to different temperatures and for different times, as detailed in Table 2. Samples reduction was followed by flushing in $\mathrm{He}$ as reported in the same Table. The total gas flow rate in both cases was $40 \mathrm{~cm}^{3} / \mathrm{min}$. The samples were then cooled to $0^{\circ} \mathrm{C}$ and several pulses of $10 \% \mathrm{O}_{2} / \mathrm{He}$ mixture were injected, until the peak area of the outcoming oxygen became constant (sample saturation). The outlet gas during both TPR and oxygen pulse chemisorption analysis was monitored and quantified by means of a thermal conductivity detector (TCD), after careful calibration. A similar apparatus, equipped with a quadrupolar mass spectrometric detector (MKS, PPT Residual Gas Analyser) was used to identify the nature of the effluent species. The total amount of oxygen adsorbed was expressed as chemisorbed oxygen volume per gram of sample $\left(\mathrm{Ncm}^{3} / \mathrm{g}_{\mathrm{cat}}\right)$ or per gram of $\mathrm{Ru}$. Metal dispersion and Ru surface area were calculated as described in [31].

\subsection{Activity tests}

Activity tests were performed by means of a bench scale, fixed bed, down-flow Incoloy 800 reactor. A detailed description of the apparatus and procedure is given elsewhere [2]. Briefly, the catalyst in $0.15-0.25 \mathrm{~mm}$ particle size was loaded after dilution $(1 / 22 \mathrm{vol} / \mathrm{vol})$ with quartz particles of the same size, in order to minimise the hot-spot along the catalyst bed. The catalyst was activated in situ by flowing a $\mathrm{H}_{2}+\mathrm{N}_{2}$ mixture $\left(\mathrm{H}_{2} / \mathrm{N}_{2}=\right.$ 
$1.5 / 1 \mathrm{vol} / \mathrm{vol})$, at $\mathrm{GHSV}=20,000 \mathrm{~h}^{-1}, 30 \mathrm{bar}$, while increasing temperature following different activation programmes. Standard activation (Astd) was carried out by heating by $1^{\circ} \mathrm{C} / \mathrm{min}$ up to $450^{\circ} \mathrm{C}$, maintained for $5 \mathrm{~h}$ and then decreased down to $430^{\circ} \mathrm{C}$. In order to check the effect of activation on catalytic activity, the following heating programmes were also applied: heating by $1^{\circ} \mathrm{C} / \mathrm{min}$ up to $450^{\circ} \mathrm{C}$, kept for $120 \mathrm{~h}(\mathrm{~A} 1)$, or up to $550^{\circ} \mathrm{C}$, kept for $5 \mathrm{~h}$ (A2). The reactant gas mixture was carefully purified from oxygenates by passing through a trap, packed with a proper amount of frequently regenerated, reduced Fe-based commercial ammonia synthesis catalyst.

Activity tests have been carried out under standard reaction conditions, i.e. 100 bar and $430^{\circ} \mathrm{C}$, by varying the gas mixture space velocity from GHSV $=60,000$ to $200,000 \mathrm{~h}^{-1}$. The effluent gas was bubbled in a known amount of diluted $\mathrm{H}_{2} \mathrm{SO}_{4}$, followed by titration of the residual acid with $\mathrm{NaOH}$ solution.

\section{3 - RESULTS AND DISCUSSION}

The samples were prepared following the previously optimised procedure $[2,17,25]$ (Table 1). In order to check the effect of different activation conditions and to identify the state of promoters, a single batch of $\mathrm{Ru} / \mathrm{C}$ was used for promoters deposition. No sample treatment was done after promoters impregnation, hence precursors' decomposition was expected during catalyst activation. The latter was made by temperature programmed reduction (TPR), according to the heating programmes detailed in Table 2. The reduced samples were then analysed by oxygen pulse chemisorption. TPR with $\mathrm{H}_{2}$ surely leads to the reduction of the $\mathrm{RuO}_{x}$ surface passivated layer and to the decomposition of the nitrate promoters precursor. In addition, a higher hydrogen and oxygen uptake can be expected if 
the alkaline promoters reduction occurs. On the other hand, if the structural action of $\mathrm{Ba}$ is true, a different oxygen uptake should be observed if the hypothesised $\mathrm{Ru}$ redistribution affects metal dispersion.

A further checking for support effect during activation was made by means of the comparative sample prepared with the as supplied active carbon (AC). It should be remembered that this sample does not have any practical use, due to support instability under the ammonia synthesis reaction conditions.

\section{1 - TPR analysis}

An example of TPR pattern is reported in Fig.1, relative to the R3 programme (Table 2). The blank Cs/GC sample showed a broad and very small $\mathrm{H}_{2}$ uptaking peak between 350 and $450^{\circ} \mathrm{C}$, corresponding to nitrate decomposition. Similar patterns were observed for the other blank samples. The Ru/GC sample showed a reduction peak centred at ca. $100^{\circ} \mathrm{C}$, due to the reduction of $\mathrm{RuO}_{x}$ surface species. The same peak was observed when using $A C$ as support (sample $\mathrm{Ru} / \mathrm{AC}$, not reported), but it showed much broader. The peak at higher temperature is due to incipient $\mathrm{CH}_{4}$ formation, due to poor support stability in the absence of promoters [25].

After adding the promoters the pattern radically changed, as found also by others [29,32]. The first peak shifted towards higher temperature and became much more intense. Indeed, the maximum of the first peak was found at ca. $200-250^{\circ} \mathrm{C}$ for all the singly promoted samples supported on GC. By contrast, the nitrate precursor decomposition occurred at markedly lower temperature with respect to the blank samples. It should be noticed that the TCD detector does not permit a reliable quali- and quanti- 
fication of the various species in the case of strongly overlapping contributions. The Cs$\mathrm{Ru} / \mathrm{AC}$ sample showed the same shift of the low temperature reduction peak, whereas the higher temperature peak was practically absent. Finally, the tri-promoted sample prepared from $\mathrm{RuCl}_{3}$ gave a broader reduction pattern, with higher $\mathrm{H}_{2}$ uptake, continuing even at the highest temperature (Fig. 2).

From the TPR data the following preliminary conclusions can be drawn: i) $\mathrm{H}_{2}$ uptake strongly increases for the promoted samples; ii) promoters precursors decomposition shifts to markedly lower temperature in the presence of $\mathrm{Ru}$; iii) the reduction profile is more complex and $\mathrm{H}_{2}$ uptake is higher for the Cs-promoted sample supported on GC, with respect to $A C$; iv) the chloride containing sample shows higher $\mathrm{H}_{2}$ uptake and requires a much prolonged reduction with respect to the samples prepared from a different $R u$ precursor.

\section{$3.2-\mathrm{O}_{2}$ chemisorption}

The measurements were carried out by following the procedure reported in [31] on the samples reduced as detailed in Table 2 and then flushed with He to remove the excess $\mathrm{H}_{2}$. The experiment was repeated at least three times on fresh portions of each sample. The number of repetitions was increased, when needed, to achieve a better reliability. A good agreement between consecutive measurements was always obtained with unpromoted samples, whereas varying $\mathrm{O}_{2}$ uptakes were often obtained with promoted samples, especially with Cs and K, supported on GC. The results are summarised in Table 3. No significant effect of the reduction temperature on oxygen uptake of blank samples was observed. Oxygen uptake of the Ru-containing samples is reported in the same Table 3 for every reduction programme. Ru dispersion (D) and exposed surface area $\left(\mathrm{S}_{\mathrm{Ru}}\right)$, 
calculated as described in [31], are reported for unpromoted samples only, due to oversized oxygen uptake by promoted catalysts (vide infra), leading to unreliable data.

The blank samples of the unpromoted support showed very low oxygen uptake for both supports, in line with our previous findings. The same result was obtained when adding $\mathrm{Cs}$ to the non-graphitised $\mathrm{AC}$. By contrast, progressively higher $\mathrm{O}_{2}$ uptake was observed with the alkali promoted samples supported on the graphitised GC.

The effect of the unpromoted Ru/GC sample (Table 3 and Fig.3) showed that the highest dispersion was obtained after treatment at the lowest temperature. By increasing temperature or prolonging the reduction up to 15 hours, the slightly decreasing of metal dispersion confirmed the expected sintering of $\mathrm{Ru}$.

Some differences were observed upon $\mathrm{Ba}$ addition. Indeed, a much lower amount of oxygen was uptaken by the sample treated at $300^{\circ} \mathrm{C}$, in line with the hypothesis of partial $\mathrm{Ru}$ covering by $\mathrm{BaO}[5,13,18]$. Furthermore, this excludes the reduction of this promoter at least at this temperature. When the reduction temperature was increased, a bit higher oxygen uptake was observed with respect to that uptaken by the unpromoted sample at $400^{\circ} \mathrm{C}$. However, a further increase of the reduction temperature or a longer reduction time did not show any difference in oxygen uptake with respect to the $\mathrm{Ru} / \mathrm{GC}$ catalyst.

Cs addition brought about a considerable increase of oxygen uptake (Fig. 3), as observed also by others [29]. $300^{\circ} \mathrm{C}$ seems a sufficient temperature to provoke this anomalous oxygen uptake. By contrast, prolonged reduction times seem to decrease the very high amount of oxygen uptake. Similar results were obtained with sample K-Ru/GC, ranking half way between $\mathrm{Ru} / \mathrm{GC}$ and $\mathrm{Cs}-\mathrm{Ru} / \mathrm{GC}$. However, $\mathrm{K}$ seems less effective than Cs in increasing the oxygen uptake, in spite of its much higher concentration. Indeed, this value can be compared with that of the K-GC blank sample, which exhibits oxygen uptake 
higher than Cs-GC, in contrast with the Ru-containing samples, for which oxygen overtaking is more limited for the K-promoted sample.

The extra oxygen uptake of the alkali-promoted samples can be explained in terms of reduction of the alkali metal ions during the reduction treatment, supported also by the higher intensity of the TPR pattern (Fig.1) with respect to the unpromoted sample. This hypothesis was suggested by Aika [33] and Kowalczyck [28,29], though the degree of reduction of the alkali metal is not yet completely clear. $\mathrm{Cs}^{+}$and $\mathrm{K}^{+}$reduction, at least under the present reduction conditions, seems possible if we consider chemisorbed $\mathrm{H}$ species (in equilibrium with molecular $\mathrm{H}_{2}$ ) as the reducing agent. Hence, as observed also in [34], the presence of Ru seems fundamental in order to catalyse the surface reduction of alkali metal ions, very likely through the dissociative adsorption of $\mathrm{H}_{2}$, so providing the atomic $\mathrm{H}$ needed for such a reduction. Some possible reaction pathways and the relative $\Delta G$ calculations are proposed elsewhere [33,34]. However, we have observed some overtaking of oxygen also in the case of the blank samples doped with $\mathrm{Cs}$ and $\mathrm{K}$. This can be justified by the possible reduction of these ions even in the absence of $\mathrm{Ru}$, if a proper amount of chemisorbed $\mathrm{H}$ species can form (e.g. in correspondence of some metallic impurities of the support). However, a trace of this reduction should be observed during TPR, which is not our case (Fig.1). Another possible explanation can be the oxidative interaction between the support and the alkali metal ion, leading to some oxidised surface compound (such as carbonate or carbonyl species). At the moment we don't have any evidence for this. Finally, the stability of different Cs oxide species, characterised by higher O/Cs ratio, can partly explain the higher uptake of oxygen for the Cs doped samples. However, when Ru is present, a much higher oxygen uptake was observed with $\mathrm{Cs}$, which cannot be explained on this basis only. Finally, no evidence of $\mathrm{BaO}$ reduction can be drawn from these data. However, the hypothesis of a structural action of this promoter cannot be excluded. 
Another important point is the role of the support in this reduction process. It is well known that alkaline metals can interact with graphite to form intercalation compounds $[35,36]$. Hence, it can be hypothesised that the alkaline promoters are reduced during the activation process, the reaction being favoured by the formation of intercalation compounds. It is also well known that the AC stability under the ammonia synthesis conditions is poor $[2,25,37-39]$ and that it can be improved by a proper thermal treatment and by the addition of promoters [25]. During heating in inert atmosphere, the carbon support is partially graphitised, the graphitisation degree depending on temperature and time of treatment [2]. Hence, the graphitised carbon support can help the formation of intercalation compounds with the reduced alkaline metals. This hypothesis was checked by preparing a comparative sample supported on the non-graphitised AC. The oxygen uptake of this sample, reduced at different temperatures before and after Cs addition, is reported in Table 3 and Fig.4. The unpromoted catalyst supported on AC showed a slightly higher dispersion with respect to the GC-supported one, in line with our previously reported data [31]. However, when adding $\mathrm{Cs}$ to $\mathrm{Ru} / \mathrm{AC}$, the same $\mathrm{O}_{2}$ uptake was observed, independently of the reduction temperature. This further confirms the hypothesis of Cs reduction over partially graphitised support only. Indeed, in the absence of the stabilisation effect due to the formation of the intercalated reduced promoter, neither $\mathrm{H}_{2}$ (during TPR, Fig.1) nor $\mathrm{O}_{2}$ (during chemisorption, Fig.4) over-taking was observed.

The same samples were analysed by $\mathrm{N}_{2}$ adsorption/desorption, both as prepared and after reduction at $480^{\circ} \mathrm{C}$ (Table 4). The Cs-promoted, AC-supported samples showed a little decrease of SSA after reduction at $480^{\circ} \mathrm{C}$, whereas the opposite trend was observed for the GC-supported one. One may conclude that inter-lamellar collocation of at least a part of the promoter can increase not only pore volume, but also surface area.

Furthermore, the support can play an important role also as electron transfer agent. Indeed, a hot-ring promotion has been suggested for Cs $[13,40]$. The latter would locate at 
the interface between $\mathrm{Ru}$ and the support, so to ensure electron donation between the reduced promoter and the active metal. If $\mathrm{Cs}$ is reduced and forms an intercalation compound, this scheme can be overcome. Indeed, the graphitic layer itself can act as a transfer medium for electron donation to $\mathrm{Ru}$, so maximising the promoter efficiency and possibly allowing to decrease its concentration.

Therefore, from the present data one may conclude that Cs, and, to a lower extent, $\mathrm{K}$, play an electronic promotional effect in the reaction, especially when the support is graphitised. Indeed, in the latter case the reduction of at least a part of the promoter is favoured by the stabilising formation of intercalation compounds, which maximises the promoters' activity. It should be underlined that Cs (or K) as promoters are active in ammonia synthesis also when used with $A C$, though their reduction in this case is unlikely (vide supra). Indeed, it has been shown by XPS analysis [1,25] that, even if present in their oxidised form, these promoters, as well as $\mathrm{BaO}$, show some electron-donor effect, leading to a shift of Ru binding energy. However, without proper support environment, the effect of $\mathrm{K}$ and $\mathrm{Cs}$ is very weak with respect to $\mathrm{BaO}$. As for the latter, the mentioned XPS measurements [25], later confirmed by others [18,27], show that undoubtedly $\mathrm{BaO}$ has an electronic effect. However it is hard to correlate this moderate action with its overperforming activity. Indeed, the $\mathrm{BaO}$-induced shift of $\mathrm{Ru}$ binding energy is rather low if compared with the Cs-induced one. Moreover, the calculated electronegativity of $\mathrm{BaO}$ is similar to that of $\mathrm{CsOH}$ [27]. By contrast, its effect in promoting catalyst performance is much higher than expected from these findings. Therefore, a structural effect, as hypothesised in [28] or in [41], should not be excluded.

In our previous investigation on promoters effect [25] we reported on the role of $\mathrm{Ba}$, Cs and $\mathrm{K}$ on the stability of the support towards methanation. It was found that, in addition to partial graphitisation through thermal treatment, carbon stability can be strongly improved by proper promoters addition. Indeed, $\mathrm{CH}_{4}$ formation was shifted towards higher 
temperature and decreased considerably after $\mathrm{Ba}$ addition. Further improvement was attained by adding also $\mathrm{K}$ and $\mathrm{Cs}$.

The support stabilising effect of $\mathrm{Ba}$ can be explained on the basis of a proposed model of $\mathrm{Ba}$ deposition on $\mathrm{Ru}[13,18]$. TEM images showed that $\mathrm{BaO}$ partly covers the $\mathrm{Ru}$ particles. In particular, for these catalysts it has been demonstrated that optimal $\mathrm{Ru}$ dispersion should not be too high (due to the structure sensitivity of the ammonia synthesis), so to have an average particle size of ca. $2 \mathrm{~nm}$. This would maximise the formation of the so-called B5 active sites located on steps in monolayer surface terraces. These sites seem the most active for $\mathrm{N}_{2}$ adsorption, whereas $\mathrm{H}_{2}$ can dissociate nonselectively also on other $\mathrm{Ru}$ sites (and compete with $\mathrm{N}_{2}$ ). In this scenario we can hypothesise that $\mathrm{BaO}$ can accommodate on $\mathrm{Ru}$ terrace sites, which can dissociatively adsorb $\mathrm{H}_{2}$, so limiting the concentration of surface active hydrogen which can react with the support. This would not affect catalytic activity (because $\mathrm{H}_{2}$ dissociation is not the rate determining step of the reaction), but it would strongly limit the unwanted methanation of the support, otherwise catalysed by unpromoted Ru even on graphitised carbon. The stabilising effect of $\mathrm{K}$ and $\mathrm{Cs}$ is less clear. We can hypothesise that the above mentioned formation of intercalation compounds can modify both support structure (by increasing the interlayer distance) and electronic state (by varying the Fermi level energy), so further improving support resistance.

\section{3- Catalyst activation}

On the basis of the above reported results the role of the activation step becomes more critical. Indeed, if the promoters have to be reduced and/or if catalyst reorganisation takes place, the activation step should be optimised, so to attain the best performing conditions. This was particularly stressed by Hinrichsen et al. [30], who showed the need 
of prolonged high temperature reduction to allow high and stable catalytic activity for Ba$\mathrm{Ru} / \mathrm{MgO}$ catalysts. Fig. 1 and 3 show that, from the point of view of Ru dispersion and possible promoters reduction, there is no need of a too high pre-treatment temperature and that a reduction time as long as $15 \mathrm{~h}$ seems detrimental from both points of view for $\mathrm{Ru} / \mathrm{C}$. To check the effect of activation on catalytic activity some ammonia synthesis tests have been here made after activation, under different conditions, of fresh portions of one of our best-performing catalysts. The results are reported in Fig. 5. It is evident that the increase of both the temperature and the duration of reduction brings about a decrease of catalytic activity, in line with the results reported in Fig.3, showing the decrease of oxygen uptake for the Cs-promoted sample.

A possible reason of this discrepancy between our data and those reported elsewhere [30] could be the higher tendency to sintering when the support is carbon rather than $\mathrm{MgO}$. However, we believe that the keypoint is the nature of $\mathrm{Ru}$ precursor (nitrosylnitrate in the present case, chloride in most of the other samples) requiring different and more or less drastic activation conditions. The need of catalyst washing until complete chloride elimination, for a sample prepared from $\mathrm{RuCl}_{3}$, has been already shown by us [17]. The TPR pattern (Fig.2) helps in clarifying this point. Indeed, the TCD peak does not close within the experimental time lapse, at difference with what reported for a comparative sample prepared from $\mathrm{Ru}(\mathrm{NO})\left(\mathrm{NO}_{3}\right)_{3}$. Hence, we can hypothesise that the samples prepared from $\mathrm{RuCl}_{3}$ have to be activated more drastically, so to remove chlorides, well known poisons for this catalyst $[1,17,32,34]$. This "over-activation" could be avoided by a repeated washing of the sample after Ru reduction, leading to good catalyst performance even with a shorter activation [17]. This was confirmed by monitoring the outcoming gas during catalyst activation, showing the presence of chlorides, which were not completely removed during catalyst reduction. 


\section{4 - CONCLUSIONS}

The influence of the reduction treatment under various temperature and duration conditions was analysed for a set of $\mathrm{Ru} / \mathrm{C}$ catalysts for ammonia synthesis. High $\mathrm{H}_{2}$ uptake during reduction and anomalous $\mathrm{O}_{2}$ uptake during chemisorption were observed for alkalidoped samples with graphitised carbon as support. This can be explained by the possible partial reduction of $\mathrm{Cs}$, and, to a lower extent, of $\mathrm{K}$, favoured by the formation of intercalation compounds within the lamellar graphite layers. No evidence of $\mathrm{BaO}$ reduction was observed. However, its electronic-only role seemed insufficient to justify its high promoting activity. Some hypotheses have been suggested to explain the effect of the promoters in improving the support stability against methanation. In particular $\mathrm{Ba}$ can cover some $\mathrm{Ru}$ terrace sites, so reducing the activation of $\mathrm{H}_{2}$ for this unwanted reaction. Finally, the nature of $\mathrm{Ru}$ precursor plays a considerable role in defining the activation procedure of the final catalyst.

\section{REFERENCES}

1. S.R. Tennison, in: J.R. Jennings (Ed.), Catalytic Ammonia Synthesis, Fundamentals and Practice, Plenum Press, New York, 1991, p. 303.

2. L. Forni, D. Molinari, I. Rossetti, N. Pernicone, Appl. Catal. A: General 185 (1999) 269.

3. I. Rossetti, N. Pernicone, F. Ferrero, L. Forni, Ind. Eng. Chem. Res., 45 (2006) 4150.

4. Z. Kowalczyk, S. Jodzis, J. Sentek, Appl. Catal. A: General, 138 (1996) 83.

5. C. Liang, Z. Wei, Q. Xin, C. Li, Appl. Catal. A: General, 208 (2001) 193.

6. S.M. Yunusov, V.A. Likholobov, V.B. Shur, Appl. Catal. A: Gen., 158 (1997) L35.

7. K. Aika, H. Hori, A. Ozaki, J. Catal. 27 (1972) 124.

8. S.E. Siporin, R.J. Davis, W. Rarog-Pilecka, D. Szmigiel, Z. Kowalczyk, Catal. Lett., $93(1-2)(2004) 61$.

9. J. Kubota, K. Aika, J. Phys. Chem., 98(44) (1994) 11293.

10. D. Szmigiel, W. Raróg-Pilecka, E. Miśkiewicz, M. Gliński, M. Kielak, Z. Kaszkur, Z. Kowalczyk, Appl. Catal. A: General, 273 (2004) 105.

11. O. Hinrichsen, F. Rosowski, M. Muhler, G. Ertl, Chem. Eng. Sci., 51 (1996) 1683. 
12. W. Rarog, Z. Kowalczyk, J. Sentek, D. Skladanowski, J. Zielinski, Catal. Lett., 68 (2000) 163.

13.Z. Kowalczyk, M. Krukowski, W. Raróg-Pilecka, D. Szmigiel, J. Zielinski, Appl.

Catal. A: General, 248 (2003) 67.

14.P. Moggi, G. Albanesi, G. Predieri, G. Spoto, Appl. Catal. A: Gen., 123 (1995) 145.

15. K. Aika, T. Takano, S. Murata, J. Catal., 136 (1992) 126.

16. S.M. Yunusov, E.S. Kalyuzhnaya, B.L. Moroz, A.S. Ivanova, T.V. Reshetenko, L.B. Avdeeva, V.A. Likholobov, V.B. Shur, J. Molec. Catal. A: Chemical, 219 (2004) 149.

17.I. Rossetti, L. Forni, Appl. Catal. A: General, 282 (2005) 315.

18. T.W. Hansen, P.L. Hansen, S. Dahl, C.J.H. Jacobsen, Catal. Lett., 84 (2002) 7.

19.B.C. McClaine, R.J. Davis, J. Catal., 210 (2002) 387.

20.S. Dahl, A. Logadottir, R.C. Egeberg, J.H. Larsen, I. Chorkendorff, E. Tornqvist, J.K. Norskov, Phys. Rev. Lett., 83 (1999) 1814.

21.S. Dahl, E. Tornqvist, I. Chorkendorff, J. Catal. 192 (2000) 381.

22. J. Zambelli, J. Trost, J. Wintterlin, G. Ertl, Phys. Rev. Lett., 76 (1996) 795.

23. C.J.H. Jacobsen, S. Dahl, P.L. Hansen, E. Tornqvist, L. Jensen, H. Topsoe, D.V. Prip, P.B. Moenshaug, I. Chorkendorff, J. Mol. Catal. A: Chemical, 163 (2000) 19.

24. Y. Kadowaki, K. Aika, J. Catal., 161 (1996) 178.

25. I. Rossetti, N. Pernicone, L. Forni, Appl. Catal. A: Gen., 208 (2001) 271.

26. O. Hinrichsen, F. Rosowski, M. Muhler, G. Ertl, Chem. Eng. Sci., 51 ( 1996) 1683.

27. H.S. Zeng, K. Inazu, K. Aika, J. Catal., 211 (2002) 33.

28. M. Guraya, S. Sprenger, W. Raróg-Pilecka, D. Szmigiel, Z. Kowalczyk, M. Muhler, Appl. Surf. Sci., 238 (2004) 77.

29. D. Lomot, Z. Karpinski, W. Raróg-Pilecka, D. Szmigiel, Z. Kowalczyk, Polish Journal of Chemistry, 78 (2004) 163.

30. H. Bielawa, O. Hinrichsen, A. Birkner, M. Muhler, Angew. Chem. Int. Ed., 40(6) (2001) 1061.

31.I. Rossetti, N. Pernicone, L. Forni, Appl. Catal. A: Gen. 248 (2003) 97.

32. K. Aika, K. Shimazaki, Y. Hattori, A. Ohya, S. Ohshima, K. Shirota, A. Ozaki, J. Catal., 92 (1985) 296.

33. T. Hikita, Y. Kadowaki, K. Aika, J. Phys. Chem., 95 (1991) 9396.

34. N.B. Shitova, N.M. Bobrynkin, A.S. Noskov, T.P. Prosvirin, V.I. Bukhtiyarov, D.T. Kochubel, P.G. Tsyrul'nikov, D.A. Shlyapin, Kinet. And Catal., 45(3) (2004) 414.

35. M.R.C. Hunt, P.J. Durston, R.E. Palmer, Surf. Sci., 364 (1996) 266.

36. N. Azukawa, M. Watanabe, T. Tajima, Y. Soneda, R. Matsumoto, Y. Takahashi, Synthetic Metals, 125 (2002) 147.

37. C. Liang, Z. Li, J. Qiu, C. Li, J. Catal., 211 (2002) 278.

38. US Patent 4,163,775, 7 August 1979, to BP Co.

39. I. Rossetti, N. Pernicone, L. Forni, Catal. Today, 102-103 (2005) 219.

40. A.Kotarba, J. Dmytrzyk, W. Raróg-Pilecka, Z. Kowalczyk, Appl. Surf. Sci., 207 (2003) 327.

41. W. Raróg-Pilecka, E. Miśkiewicz, D. Szmigiel, Z. Kowalczyk, J. Catal., 231 (2005) 11. 
Table 1: Composition of the samples prepared.

\begin{tabular}{|c|c|c|c|c|c|c|c|c|c|}
\hline Catalyst & support $^{\mathrm{b}}$ & $\begin{array}{c}\mathrm{K} / \mathrm{C} \\
\text { wt\% }\end{array}$ & $\begin{array}{c}\mathrm{Cs} / \mathrm{C} \\
\text { wt\% }\end{array}$ & $\begin{array}{c}\mathrm{Ba} / \mathrm{C} \\
\text { wt\% }\end{array}$ & $\begin{array}{c}\text { Blank } \\
\text { samples }\end{array}$ & support $^{\mathrm{b}}$ & $\begin{array}{c}\mathrm{K} / \mathrm{C} \\
\text { wt\% }\end{array}$ & $\begin{array}{c}\mathrm{Cs} / \mathrm{C} \\
\text { wt\% }\end{array}$ & $\begin{array}{c}\mathrm{Ba} / \mathrm{C} \\
\text { wt\% }\end{array}$ \\
\hline $\mathrm{Ru} / \mathrm{GC}$ & $\mathrm{GC}$ & - & - & - & - & - & - & - & - \\
\hline $\mathrm{Cs}-\mathrm{Ru} / \mathrm{GC}$ & $\mathrm{GC}$ & - & 5.69 & - & $\mathrm{Cs} / \mathrm{GC}$ & $\mathrm{GC}$ & - & 6.32 & - \\
\hline $\mathrm{Ba}-\mathrm{Ru} / \mathrm{GC}$ & $\mathrm{GC}$ & - & - & 3.63 & $\mathrm{Ba} / \mathrm{GC}$ & $\mathrm{GC}$ & - & - & 3.84 \\
\hline $\mathrm{K}-\mathrm{Ru} / \mathrm{GC}$ & $\mathrm{GC}$ & 4.81 & - & - & $\mathrm{K} / \mathrm{GC}$ & $\mathrm{GC}$ & 4.61 & - & - \\
\hline $\mathrm{Ru} / \mathrm{AC}$ & $\mathrm{AC}$ & - & - & - & - & - & - & - & - \\
\hline $\mathrm{Cs}-\mathrm{Ru} / \mathrm{AC}$ & $\mathrm{AC}$ & - & 4.64 & - & $\mathrm{Cs} / \mathrm{AC}$ & $\mathrm{AC}$ & - & 4.74 & - \\
\hline
\end{tabular}

a Ru loading: $\mathrm{Ru} / \mathrm{C}=3.8 \mathrm{wt} \%$

b GC: graphitised carbon, SSA $=280 \mathrm{~m}^{2} / \mathrm{g}$; AC: active carbon, $\mathrm{SSA}=1400 \mathrm{~m}^{2} / \mathrm{g}$

Table 2: TPR programs used to study the effect of temperature and time of reduction.

\begin{tabular}{|c|cc|cc|}
\hline \multirow{2}{*}{ Programme } & \multicolumn{2}{|c|}{ Reduction $^{\mathrm{a}}$} & \multicolumn{2}{c|}{ Flushing $^{\mathrm{b}}$} \\
\cline { 2 - 5 } & $\mathrm{T}$ & time $(h)$ & T & time $(h)$ \\
\hline R1 & 300 & 1 & 350 & 1 \\
R2 & 400 & 1 & 450 & 1 \\
R3 & 480 & 1 & 480 & 2 \\
R4 & 400 & 5 & 450 & 1 \\
R5 & 400 & 15 & 450 & 1 \\
\hline
\end{tabular}

${ }^{2}$ TPR: $5 \% \mathrm{H}_{2} /$ Ar mixture, total flow rate: $40 \mathrm{~cm}^{3} / \mathrm{min}$, heating rate: $10^{\circ} \mathrm{C} / \mathrm{min}$

${ }^{b}$ flushing with $\mathrm{He}$, flow rate: $40 \mathrm{~cm}^{3} / \mathrm{min}$, heating rate: $10^{\circ} \mathrm{C} / \mathrm{min}$ 
Table 3: $\mathrm{O}_{2}$ uptake of various samples. Reduction programmes as detailed in Table 2.

$S_{R u}=S u r f a c e$ area of exposed $R u, D=R u$ dispersion, both calculated as reported in [31].

\begin{tabular}{|c|c|c|c|c|c|c|}
\hline Sample & Programme & $\begin{array}{c}\mathbf{V}_{\text {blank }} \\
\mathrm{Ncm}^{3} / g_{\text {cat }}\end{array}$ & $\begin{array}{c}\mathbf{V}_{\text {cat }} \\
\mathrm{Ncm}^{3} / \mathbf{g}_{\text {cat }}\end{array}$ & $\begin{array}{c}\mathbf{V}_{\mathbf{R u}} \\
\mathrm{Ncm}^{3} / \mathrm{g}_{\mathrm{Ru}}\end{array}$ & $\begin{array}{c}\mathbf{S}_{\mathbf{R u}} \\
\mathrm{m}^{2} / \mathrm{g}_{\mathrm{Ru}}\end{array}$ & D \\
\hline \multirow{5}{*}{$\mathrm{Ru} / \mathrm{GC}$} & R1 & 0.2 & 2.41 & 62.17 & 205.15 & $55.95 \%$ \\
\hline & $\mathrm{R} 2$ & 0.2 & 1.68 & 41.83 & 138.04 & $37.65 \%$ \\
\hline & R3 & 0.2 & 1.67 & 41.44 & 136.76 & $37.30 \%$ \\
\hline & $\mathrm{R} 4$ & 0.2 & 1.71 & 44.16 & 145.72 & $39.74 \%$ \\
\hline & R5 & 0.2 & 1.41 & 34.49 & 113.82 & $31.04 \%$ \\
\hline \multirow{5}{*}{$\begin{array}{c}\text { Cs- } \\
\text { Ru/GC }\end{array}$} & R1 & 1.20 & 3.87 & 77.68 & 7 & I \\
\hline & $\mathrm{R} 2$ & 1.20 & 3.80 & 77.11 & 1 & 1 \\
\hline & R3 & 1.20 & 3.94 & 79.74 & 1 & 1 \\
\hline & R4 & 1.20 & 2.97 & 52.05 & 1 & 1 \\
\hline & R5 & 1.20 & 3.04 & 54.01 & 1 & 1 \\
\hline \multirow{5}{*}{$\begin{array}{c}\mathrm{Ba}- \\
\mathrm{Ru} / \mathrm{GC}\end{array}$} & $\overline{\mathrm{R} 1}$ & 0.40 & 0.91 & 14.70 & 1 & 1 \\
\hline & R2 & 0.40 & 2.52 & 61.76 & 1 & 7 \\
\hline & R3 & 0.40 & 1.78 & 39.41 & 1 & 1 \\
\hline & R4 & 0.40 & 1.62 & 34.68 & 7 & I \\
\hline & R5 & 0.40 & 1.71 & 37.25 & 1 & 1 \\
\hline \multirow{3}{*}{ K-Ru/GC } & $\mathrm{R} 1$ & 1.88 & 2.95 & 33.89 & I & I \\
\hline & $\mathrm{R} 2$ & 1.88 & 2.65 & 24.87 & 1 & 1 \\
\hline & R3 & 1.88 & 2.59 & 23.31 & 1 & 1 \\
\hline \multirow{3}{*}{$\mathrm{Ru} / \mathrm{AC}$} & $\overline{\mathrm{R} 1}$ & 0.20 & 2.53 & 65.39 & 215.79 & $58.85 \%$ \\
\hline & $\mathrm{R} 2$ & 0.20 & 2.02 & 51.18 & 168.89 & $46.06 \%$ \\
\hline & R3 & 0.20 & 2.51 & 64.82 & 213.91 & $58.34 \%$ \\
\hline \multirow{3}{*}{$\begin{array}{c}\text { Cs- } \\
\text { Ru/AC }\end{array}$} & R1 & 0.20 & 2.47 & 67.74 & 223.53 & $60.96 \%$ \\
\hline & $\mathrm{R} 2$ & 0.20 & 2.07 & 52.42 & 172.97 & $47.17 \%$ \\
\hline & R3 & 0.20 & 2.54 & 69.95 & 230.83 & $59.55 \%$ \\
\hline
\end{tabular}


Table 4: Specific surface area $(S S A)$, Pore volume $\left(V_{p}\right)$ and average pore diameter $\left(D_{A v}\right)$ of selected samples before and after reduction (ramp R3).

\begin{tabular}{|c|c|c|c|c|c|c|}
\cline { 2 - 7 } \multicolumn{1}{c|}{} & \multicolumn{3}{c|}{ Fresh sample } & \multicolumn{3}{c|}{ After reduction at $480^{\circ} \mathbf{C}$} \\
\hline Sample & $\begin{array}{c}\text { SSA } \\
\left(\mathrm{m}^{2} / \mathrm{g}\right)\end{array}$ & $\begin{array}{c}\mathbf{V}_{\mathbf{p}} \\
\left(\mathrm{cm}^{3} / \mathrm{g}\right)\end{array}$ & $\begin{array}{c}\mathbf{D}_{\mathbf{a v}} \\
(\mathrm{nm})\end{array}$ & $\begin{array}{c}\mathbf{S S A} \\
\left(\mathrm{m}^{2} / \mathrm{g}\right)\end{array}$ & $\begin{array}{c}\mathbf{V}_{\mathbf{p}} \\
\left(\mathrm{cm}^{3} / \mathrm{g}\right)\end{array}$ & $\begin{array}{c}\mathbf{D}_{\mathbf{a v}} \\
(\mathrm{nm})\end{array}$ \\
\hline $\mathbf{C s} / \mathbf{G C}$ & 205 & 0.34 & 67 & 253 & 0.44 & 70 \\
\hline $\mathbf{C s} / \mathbf{A C}$ & 1164 & 0.69 & 23 & 1130 & 0.65 & 23 \\
\hline $\mathbf{R u} / \mathbf{G C}$ & 180 & 0.22 & 48 & 169 & 0.22 & 52 \\
\hline $\mathbf{C s}-\mathbf{R u} / \mathbf{G C}$ & 119 & 0.15 & 49 & 150 & 0.22 & 59 \\
\hline $\mathbf{R u} / \mathbf{A C}$ & 968 & 0.59 & 24 & 962 & 0.54 & 24 \\
\hline $\mathbf{C s}-\mathbf{R u} / \mathbf{A C}$ & 972 & 0.47 & 24 & 953 & 0.37 & 24 \\
\hline
\end{tabular}

\section{FIGURE CAPTIONS}

Fig. 1: Example of TPR pattern (programme R3, Table 2).

Fig. 2: TPR analysis of a Cs+Ba+K-Ru/GC sample prepared from $\mathrm{RuCl}_{3} \cdot 3 \mathrm{H}_{2} \mathrm{O}$. Reduction programme R2, Table 2.

Fig. 3: Oxygen uptake vs. reduction treatment for variously promoted GC samples.

Fig. 4: Effect of the support on oxygen uptake of the unpromoted and Cs-doped samples.

Fig. 5: Dependence of catalytic activity on activation temperature and time. Heating rate: $1^{\circ} \mathrm{C} / \mathrm{min}$. 


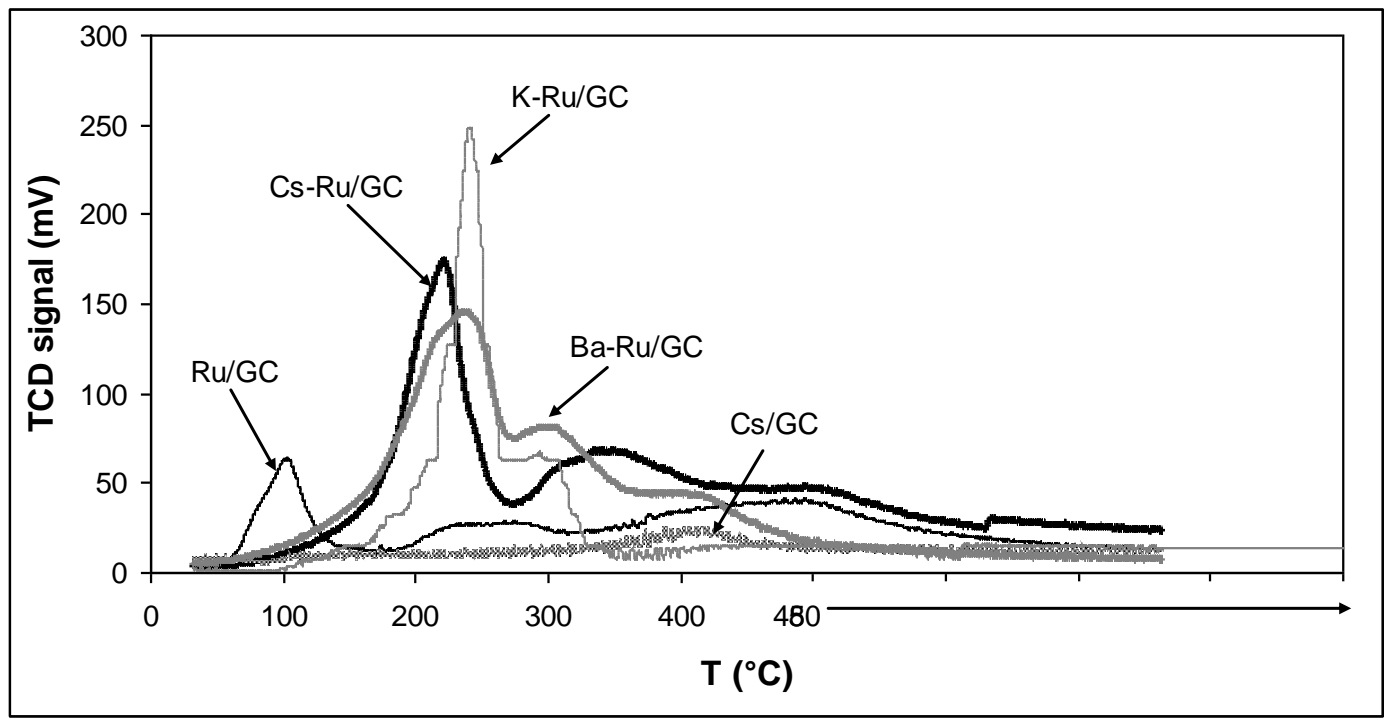

Fig. 1

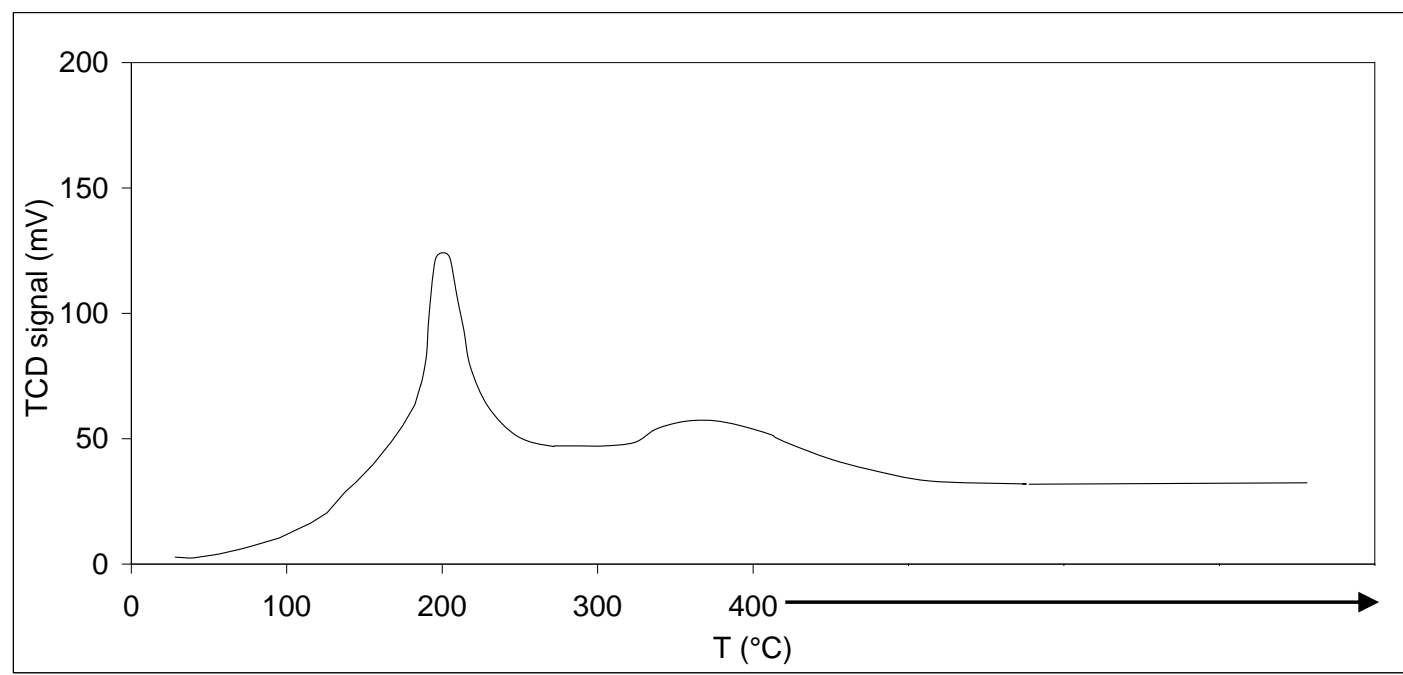

Fig. 2 


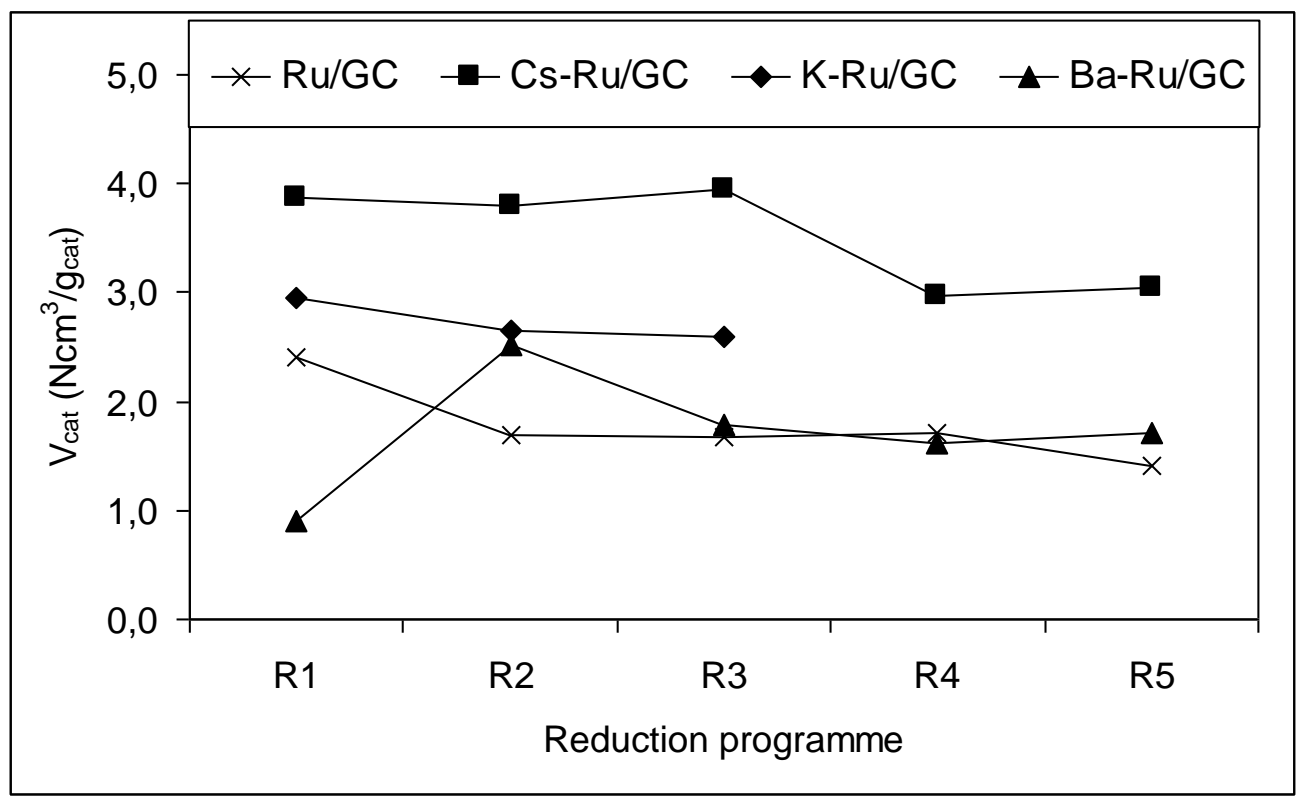

Fig. 3

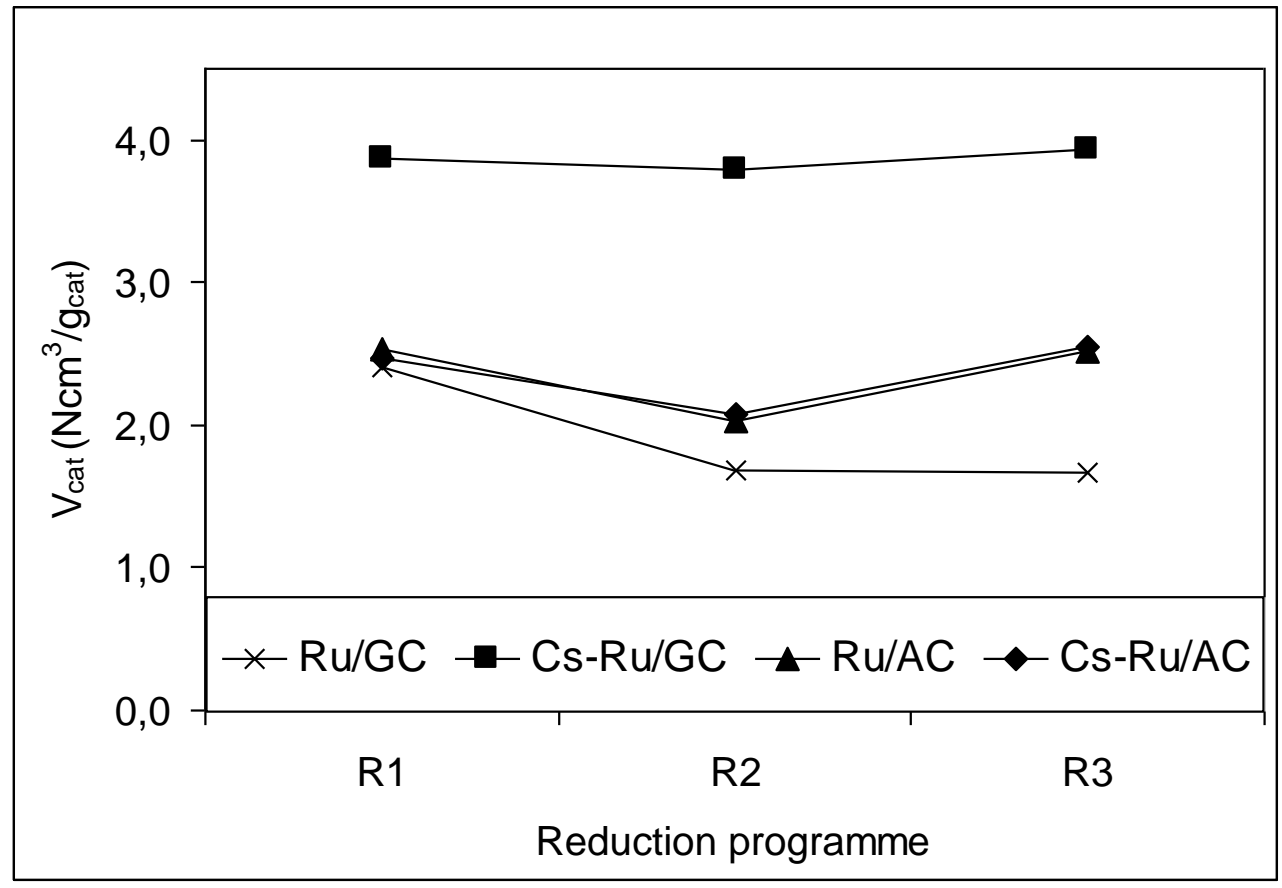

Fig. 4 


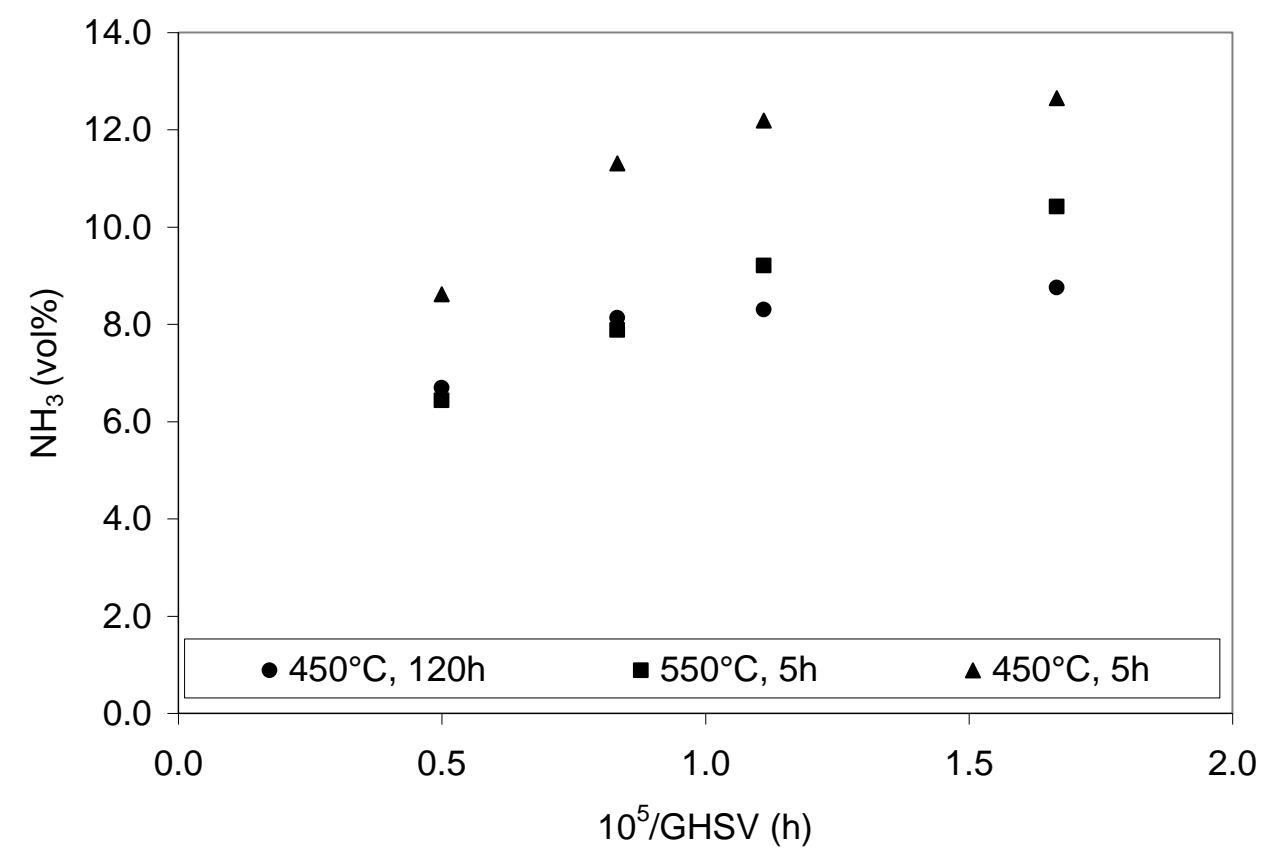

Fig.5 